Article

\title{
An Improvement of a Fuzzy Logic-Controlled Maximum Power Point Tracking Algorithm for Photovoltic Applications
}

\author{
Woonki Na ${ }^{1}$, Pengyuan Chen ${ }^{1}$ and Jonghoon Kim ${ }^{2, *}$ \\ 1 Electrical and Computer Engineering, California State University, Fresno, CA 93740, USA; \\ wkna@csufresno.edu (W.N.); pycsonar@gmail.com (P.C.) \\ 2 Electrical Engineering, Chungnam National University, Daejeon 34134, Korea \\ * Correspondence: whdgns0422@cnu.ac.kr; Tel.: +82-42-821-5657
}

Academic Editor: Alejandro Pérez-Rodríguez

Received: 31 December 2016; Accepted: 14 March 2017; Published: 30 March 2017

\begin{abstract}
This paper presents an improved maximum power point tracking (MPPT) algorithm using a fuzzy logic controller (FLC) in order to extract potential maximum power from photovoltaic cells. The objectives of the proposed algorithm are to improve the tracking speed, and to simultaneously solve the inherent drawbacks such as slow tracking in the conventional perturb and observe ( $\mathrm{P}$ and $\mathrm{O})$ algorithm. The performances of the conventional $\mathrm{P}$ and $\mathrm{O}$ algorithm and the proposed algorithm are compared by using MATLAB/Simulink in terms of the tracking speed and steady-state oscillations. Additionally, both algorithms were experimentally validated through a digital signal processor (DSP)-based controlled-boost DC-DC converter. The experimental results show that the proposed algorithm performs with a shorter tracking time, smaller output power oscillation, and higher efficiency, compared with the conventional $\mathrm{P}$ and $\mathrm{O}$ algorithm.
\end{abstract}

Keywords: PV; P and O; MPPT; fuzzy logic control; DC-DC converter

\section{Introduction}

As the demand for solar energy is dramatically increasing, solar energy applications have been massively studied for the last few decades. Solar panels can conveniently convert the received light energy to electricity without any pollution. However, the characteristics of any solar panel heavily depend on irradiation and temperature conditions in terms of the photovoltaic voltage and current [1]. To achieve the maximum power point (MPP) of photovoltaics, MPPT algorithms are normally used. Among fundamental MPPT algorithms, the incremental conductance (INC) algorithm mainly relies on the tangential value of the photovoltaic (PV) operation point to predict the right direction of the maximum power point (MPP). The fixed step-size INC algorithm aims at stability and effectiveness of the algorithm due to the fact that adaptive step-size will adversely affect the MPPT controller under certain circumstances with noise and environmental changes, while the disadvantage of the fixed step-size INC is the slow response to the insolation condition changes [2]. The other popular MPPT algorithm, perturb and observe ( $\mathrm{P}$ and $\mathrm{O}$ ) can iteratively perturb the PV voltage and observe the changes in PV power so that it can continuously move the operation point along the direction towards the MPP. The P and O algorithm does not involve derivative operations [3], hence, it would have easy implementation. However, the conventional $\mathrm{P}$ and $\mathrm{O}$ algorithm is exposed to the same issue as the INC algorithm, in which the tracking speed has to be sacrificed in order to improve MPPT efficiency, and to suppress the steady-state oscillation. To enhance MPPT control, several MPPT techniques have been investigated for creating adaptive perturbing step-sizes [4,5]. Due to the nature of the P-V characteristics of solar cells, an increase in PV voltage will result in a decrease 
in PV current. Additionally, PV power will eventually converge to zero as long as the PV voltage monotonously increases to the open-circuit voltage. Based on this nature, in [6], a discrete-time PI controller was proposed for MPPT control. The error signal of this PI controller is the change in PV power caused by operation point shifting, and the output signal of this PI controller is the step-size of the perturbation offset for the next perturbation. This PI controller is to automatically generate an adaptive step-size with simple control parameters. In fact, the gains of this controller are to be also adaptive under the changeable environmental conditions. Moreover, to reduce the steady-state error of this PI controller, the limits of this PI controller should be changed by considering variable P-V characteristics of solar cells. In [7], the authors adopted the sliding mode control (SMC) strategy for achieving the maximum power point (MPP) and selected the sliding surface where the derivation of PV operation point equals zero. According to the nature of SMC, chattering around the sliding surface can be seen in most cases, in which this chattering is related to the steady-state power oscillation. This chattering issue could keep the SMC from generating adaptive step-size. In [8,9], the authors directly change the duty-ratios of switching signals where such perturbations in duty-ratios are used as variables. The advantage of the MPPT controllers in [8,9] is that the MPPT controllers do not necessarily deal with PV voltage regulation or PV current regulation, so the complicated programing can be avoided. The disadvantage of this type of controller is that desired MPPT efficiency and accuracy cannot be guaranteed, as suggested in [10,11]. In [10-13], artificial neural networks (ANN) were adopted to enhance the MPPT algorithm in terms of accelerating the tracking speed and reducing steady-state power oscillation. The ANN-based MPPT algorithm generally demonstrates a better performance compared to traditional MPPT algorithms, such as $\mathrm{P}$ and $\mathrm{O}$, INC, and hill climbing. To improve the robustness of the ANN based MPPT algorithm, multiple parameters of photovoltaic products are normally required to train the ANN and calculate the optimized weight coefficients. Under different environmental conditions, such as temperature, insolation, and shading patterns, solar panels can present various $\mathrm{P}-\mathrm{V}$ characteristics, which means that the optimized weight coefficients of ANN could be changed to achieve the best solution for each case. In fact, weight parameters of ANNs are fixed in real-time control systems. Therefore, such ANNs may not demonstrate the best performance under all environmental conditions. For reducing the complexity of design of the MPPT algorithm, fuzzy logic control (FLC)-based MPPT algorithms have been proposed in [14-22]. Unlike ANNs, the FLC design is required to recognize patterns of P-V characteristics of photovoltaics under different operating conditions. The fuzzy logic controller used for MPPT will be designed based on those recognized patterns. In [14-18], the input signals of FLCs mainly consist of PV voltage, $\mathrm{PV}$ current, incremental change in the PV voltage, incremental change in the PV power, and the ratios of the incremental change in PV power to the change in PV voltage or current. In [19], the change in PV power, $\Delta P$ and change in PV current, $\Delta I$ are selected as the input signals to FLC. According to the PVs' characteristics, the derivative of PV power with respect to the PV current is zero at the MPP. Additionally, the PV power will decay to zero as the PV voltage increases to the open-circuit voltage. The output of the FLC suggested in [19] is the duty-ratio, D. The maximum step-size of this duty-ratio is about $0.8 \%$ so that no large step-up or -down change in PV current can be expected. In this case, the transition of such FLC-controlled PV system responding to the rapid weather change may be slow. In [20], the authors combined ANN with FLC for improving the MPPT performance under shading conditions. This ANN was used for estimating the optimal PV voltage and PV power, while this FLC was used as an actuator for voltage regulations. The complicated calculations proposed in [20] can indeed improve the MPPT algorithm in terms of tracking speed and convergence to the global MPP under shading conditions. However, high-performance microcontrollers are generally needed for this complex algorithm, and the additional cost of such PV systems could be expensive. In [19], this FLC can only demonstrate the tracking speed and small oscillation under the ideal cases in which the insolation and temperature conditions are relatively stable. In fact, the environmental condition variations may introduce unexpected factors to this control algorithm and further make this FLC algorithm unstable. There is also much research related to improving FLC-based MPPT 
algorithms [21-23]. Even though FLC-based algorithms may differ in complexity and effectiveness, the strategies of the algorithms generally consist of three stages: estimation, execution, and observation. The significant stage among those three stages is estimation. Knowing that the P-V characteristics of solar cells can vary at different moments in a day, to be efficient, the MPPT algorithm should have capability to recognize variation of $\mathrm{P}-\mathrm{V}$ characteristics of solar cells and re-evaluate the operating status of the PV system. In this paper, an improved FLC-based MPPT algorithm with a self-evaluation mechanism is proposed. The two inputs of the proposed FLC are the changes in PV voltage $(\Delta V)$, and the derivative of power with respect to voltage, $(\Delta \mathrm{P} / \Delta \mathrm{V})$. To simplify the system structure, no irradiation and temperature signal is needed in the proposed FLC. The objective of the proposed FLC is to optimize the $\mathrm{P}$ and $\mathrm{O}$ algorithm in terms of accelerating tracking speed, suppressing steady-state power oscillations, and enhancing the robustness of the algorithm. In Section 2, the issues in the conventional $\mathrm{P}$ and $\mathrm{O}$ algorithm are discussed. In Section 3, the methodologies of designing the proposed FLC for MPPT control are explained. Simulation results of the proposed FLC algorithm and conventional P and O MPPT are compared in Section 4.1. Section 4.2 shows experimental results for the validation of the proposed FLC algorithm for PV applications. Section 5 concludes the paper.

\section{Issues in the Conventional $P$ and $O$ Algorithm}

The objective of the $\mathrm{P}$ and $\mathrm{O}$ algorithm is to shift the operation point $(\mathrm{V}, \mathrm{P})$ toward the MPP by continuously perturbing the PV voltage or PV current with a fixed step size. To illustrate the nonlinear characteristics of solar cells, Figures 1 and 2 present current versus voltage (I-V), and power versus voltage (P-V) curves of a commercial solar panel, SW-260-mono [24] operating at different irradiation conditions.

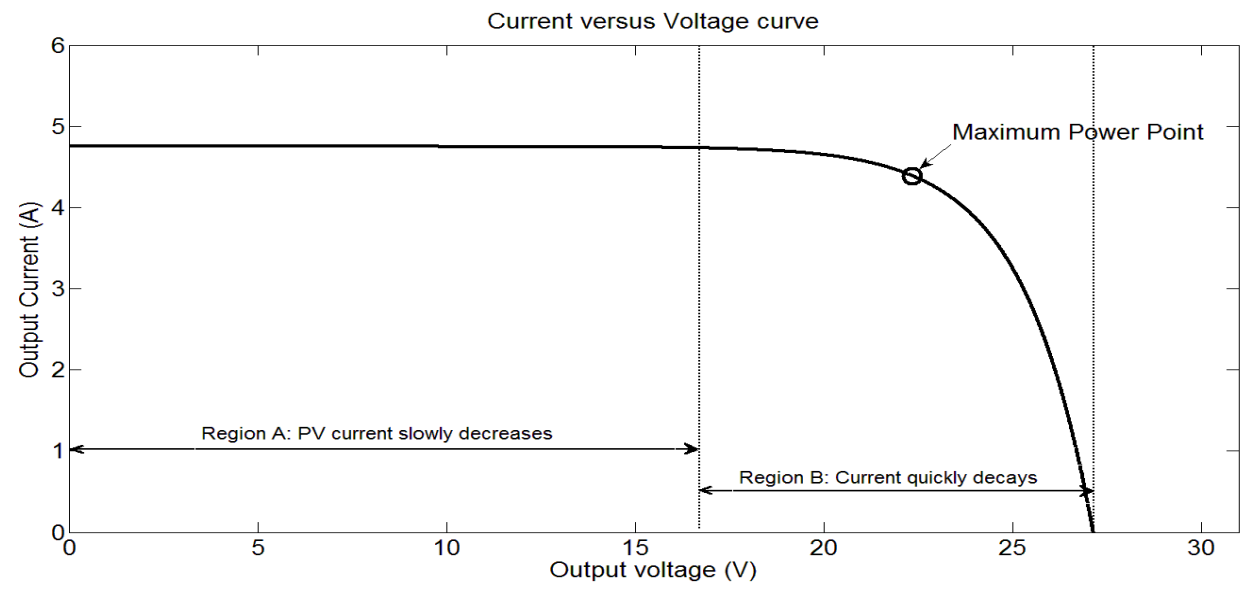

Figure 1. Ideal I-V curve.

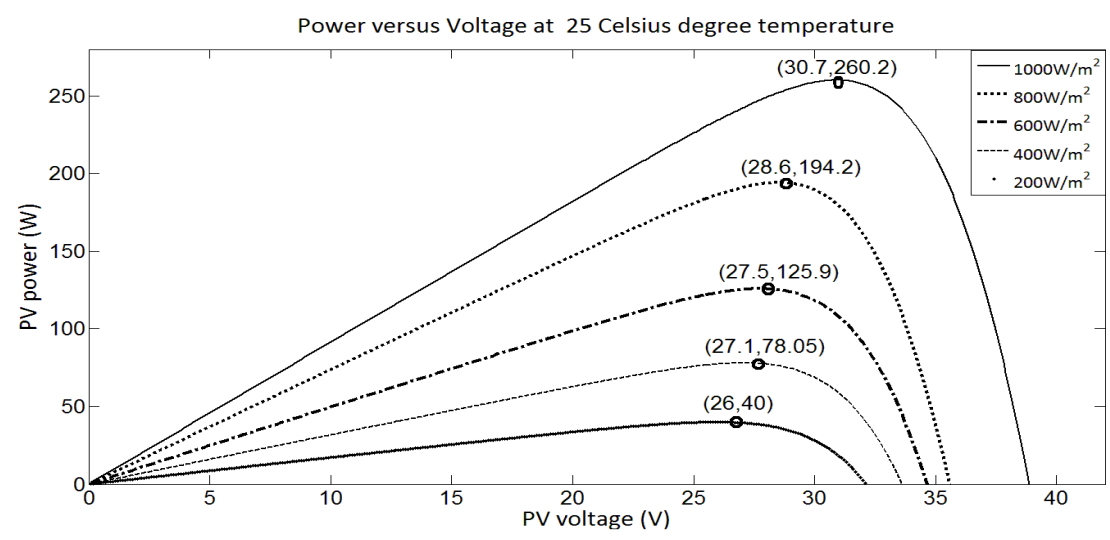

Figure 2. P-V cruves of SW-260-mono operating. 
In Figure $3, \mathrm{P}_{1}$ through $\mathrm{P}_{3}$ are three consecutive locations of the PV operation point, and shifting of the operation point is conducted by the MPPT algorithm. $\mathrm{S}_{1}$ through $\mathrm{S}_{6}$ are six possibilities that can be observed in the tracking progress of the traditional $\mathrm{P}$ and $\mathrm{O}$. For example, the case that $\mathrm{S}_{1}$ consists of several steps: (1) the PV voltage increases; (2) the operation point moves from $\mathrm{P}_{1}$ to $\mathrm{P}_{2}$; (3) an increase in the PV power is observed; (4) the PV voltage keeps increasing because the direction of the previous perturbation results in an increase in PV power; (5) the operation point moves from $\mathrm{P}_{2}$ to $\mathrm{P}_{3}$. As shown in the case $S_{3}$, a decrease in PV voltage can lead the PV power to increase so that the PV voltage keeps decreasing. Sometimes, the direction of perturbation iteratively changes, especially whenever the operation point is located within the region near the real MPP such as $S_{4} \sim S_{6}$. For instance, in $S_{4}$ in Figure 3, the decrease in the PV power causes that the operation point moves from $P_{1}$ to $P_{2}$, and a decrease in PV power can be observed. To increase the PV power, then the direction of the following perturbation $\left(P_{2}\right.$ to $\left.P_{3}\right)$ should be inversed. For the transitions from $S_{4}$ to $S_{6}$ and the transitions from $\mathrm{S}_{6}$ to $\mathrm{S}_{4}$, the PV power will periodically increase and decrease. And this is the reason why power oscillations can be observed in a PV system.

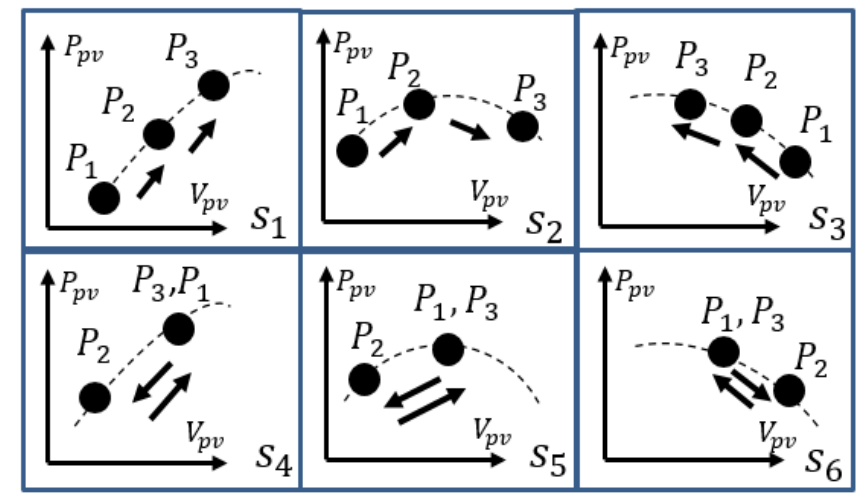

Figure 3. P and O: movement locus of the PV operation point.

Power points around MPP can generate less power, compared to the exact MPP. Plus, the direction of perturbation for the operation point will be inversed as long as decreases in power are observed. Hence, it could be predicted that the operation point will move among three reachable power points which are near MPP, as shown in Figure 4. In Figure 4, the traces of the shifting of the operation point can be concluded as two cases: $\mathrm{P}_{1} \rightarrow \mathrm{P}_{2} \rightarrow \mathrm{P}_{3}$ and $\mathrm{P}_{3} \rightarrow \mathrm{P}_{2} \rightarrow \mathrm{P}_{1}$. It is worthwhile to note that in a real PV system, $\mathrm{P}_{2}$ may not always exactly overlay MPP due to many imperfect factors such as resolutions of the switching signal and steady-state error of the voltage regulation module. In the steady state of a traditional P and O controlled PV system, the above two cases about the shifting of PV operation point will endlessly circulate so that the steady state power oscillation cannot be avoided. Fortunately, the magnitude of such steady state power oscillation can be suppressed if the step size of the perturbation of the operation point is ideally small, and is close to zero. The conventional $\mathrm{P}$ and $\mathrm{O}$ and INC algorithms using fixed step-size $(\Delta \mathrm{V})$ could waste time and energy in the low power region in which the operation point is far from the real MPP. In the simulation results shown in Figure 5, the real maximum power point voltage $\left(V_{m p p}\right)$ and maximum power point power $\left(P_{m p p}\right)$ are $27.03 \mathrm{~V}$ and 98.23 W, respectively. Different fixed step-sizes for PV voltage perturbation result in different tracking performance in terms of the tracking time and steady-state power oscillation. As shown in Figure 3, the $\mathrm{P}$ and $\mathrm{O}$ with step-size, $0.1 \mathrm{~V}$ presents a smaller steady-state power oscillation compared that of the $\mathrm{P}$ and $\mathrm{O}$ with step-size, 2.0 V. On the other hand, the $\mathrm{P}$ and $\mathrm{O}$ with step-size, $2.0 \mathrm{~V}$ shows a fast tracking speed, and the $\mathrm{P}$ and $\mathrm{O}$ with step-size $(0.1 \mathrm{~V})$ requires much more time for pushing the operation point away from the low power region (less than $80 \mathrm{~W}$ ). As a successful PV system, the tracking time should be as short as possible, meanwhile the steady state power oscillation is supposed to be as small as possible. To simultaneously achieve the above two goals, many authors [2-23] have been proposing 
concepts of adaptive perturbations in PV voltage or PV current and estimated optimal operation point. In these studies [2-23], it can be recognized that implementations of the more advanced algorithms require more powerful control units and complicated calculations. In some cases, the control strategy for PVs may be too expensive to be adopted. In this paper, two input signals, PV voltage and PV current, are fed into the FLC. Moreover, a self-evaluation mechanism is designed and combined with the multi-rule table so that no extra computation loop is needed to add into the control algorithm.

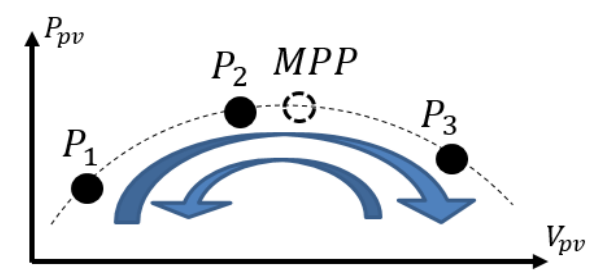

Figure 4. The operation point moves among P1, P2, and P3.

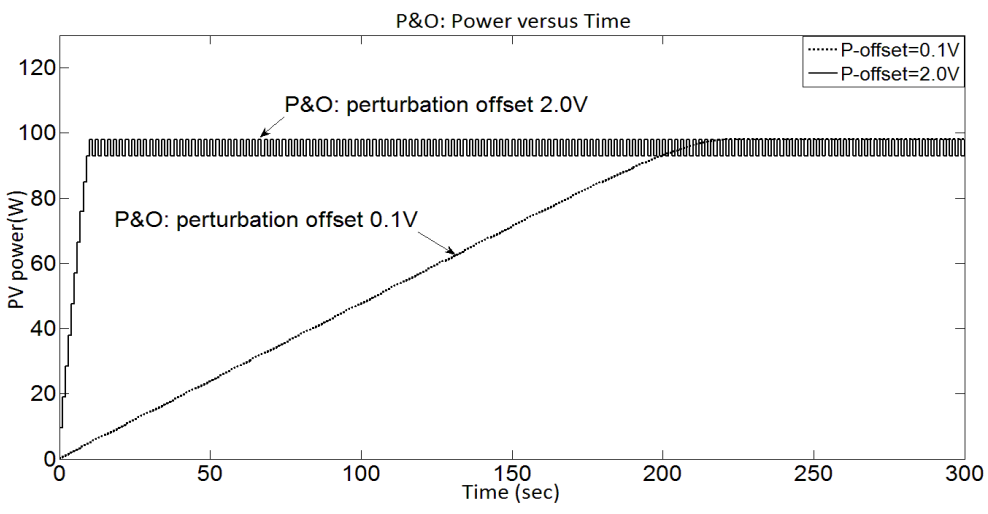

Figure 5. P and O: tracking traces with different perturbation offsets.

It is worthwhile to note that the PV DC-DC boost system can be generally modeled by the Figure 6 . The system consists of the power-stage and control module. In Figure 6, the DC link is presented by a battery. The voltage level of the DC link of a PV system is stable. In the topology shown by Figure 6, the voltage level of the solar panel is related to the voltage level of the DC link and the duty-ratio of the switching signal. Assuming that the voltage level of the DC link is constant, the perturbation in duty-ratio of the switching signal $\left(\mathrm{G}_{\mathrm{s}}\right)$ will cause a variation in the voltage level of the solar panel so that the operation point of the solar panel could shift. The key of the MPPT algorithm is to figure out the appropriate value for the duty-ratio, which can lead the solar panel to achieve its maximum power point.

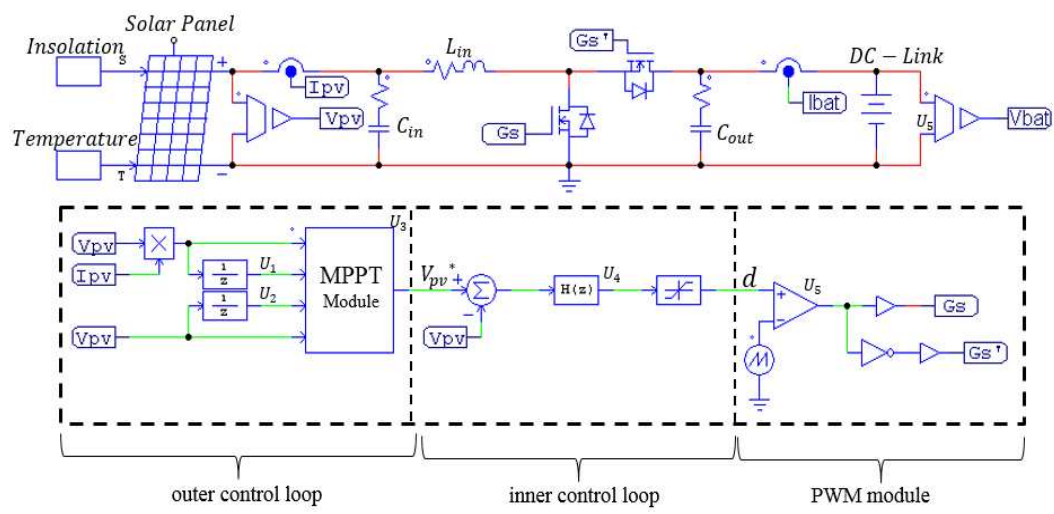

Figure 6. The general structure of PV MPPT system in a power converter. 


\section{Fuzzy Logic Controller}

As an MPPT algorithm keeps perturbing the PV operation point, the incremental changes in PV power and the previous perturbation offset can produce some non-quantitative information, i.e., the PV operation point is either far away from the MPP, or not, and the PV operation point is either on the left-hand side of the MPP or not. Although, the non-quantitative information may not directly contribute to calculations, those can still assist MPPT algorithms in terms of providing correct timings for changing perturbation offset. In consequence, the PV operation could be pushed to the MPP with few trials. For example, as seen in Figure 7, in the "PB" zone, the slope is relatively constant because the points in this zone are distant from the MPP. Thus, the perturbation offset can be enlarged for quickly pushing the operation point out of this zone, and the PV power can increase rapidly. As the operation point moves within the "PS" area, the incremental changes in PV power decrease towards zero. Hence, the perturbation offset needs to be diminished in order to carefully increase the power point to the peak value. Otherwise, the operation point may easily miss the MPP. If the operation point shifts into the "PZ" and "NZ" zones, where points within in these zones are "extremely close" to the MPP, the ideal perturbation offset should be extremely weak for suppressing power oscillations around the MPP.

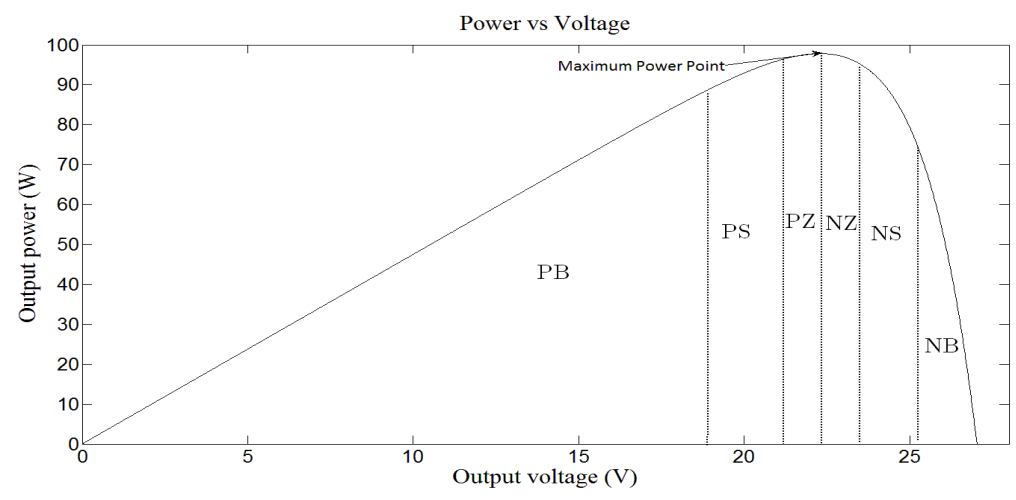

Figure 7. A sectionalized P-V curve.

The power oscillations around the MPP will be suprresed, not eliminated. The reason is that due to enviornmental changes, such as irradiation or temperature variations, photovoltaics demostrate various P-V characteristics (shown in Figure 1). The real MPP of photovoltaics may shift at any time[25-27]. As a result, the MPPT algrotihm can detect the potential change of the P-V curve by continously pertubing the operation point with extremely small offsets.

\subsection{Principles of the Proposed Fuzzy Logic Controller}

Fuzzification, logic judgment, and defuzzification are the three consecutive stages of an FLC [28]. The fundamental structure of a fuzzy logic controller is shown in Figure 8.

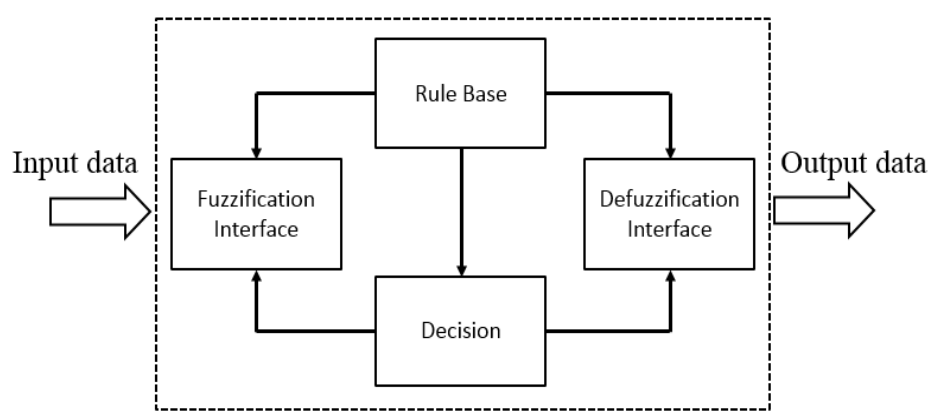

Figure 8. The structure of a fuzzy logic controller. 
At the stage of fuzzification, the numerical ratio, $\mathrm{dP} / \mathrm{dV}$ (the change in $\mathrm{PV}$ power to the change in $\mathrm{PV}$ voltage, $\Delta \mathrm{P} / \Delta \mathrm{V})$ is translated into a linguistic variable via membership functions. The numerical offset, $\mathrm{dV}$ is the previous perturbation offset, $\Delta \mathrm{V}$. " $\mathrm{dP} / \mathrm{dV}$ " and " $\mathrm{dV}$ " are two input linguistic variables of the FLC. The output of the FLC, PT is the numerical offset for the next perturbation. The two input variables of the FLC are given by Equations (1) and (2):

$$
\begin{gathered}
d P / d V=\frac{P[k]-P[k-1]}{V[k]-V[k-1]} \\
d V=V[k]-V[k-1]
\end{gathered}
$$

At the beginning of every control interval of the FLC, the numerical inputs are translated into logic linguistic elements. According to the membership functions of $d P / d V$ and $d V$, the input variables can be classified as "Positive Big", "Negative Big", "Positive Small”, "Negative Small”, "Positive Zero", and "Negative Zero". Different from binary logic controllers, FLCs not only define variables with binary logic values, 0 and 1, but also provide degrees of variables. For example, according to membership functions, the FLC may consider the slope of the present operation point as: 50\% PB, $10 \% \mathrm{PS}, 5 \% \mathrm{PZ}$, etc. Hence, descriptions for variables could be more diverse and precise in terms of logic control. At the stage of the logic judgment, given fuzzified input variables, the FLC will look up its rule-base to find out all reasonable logic consequences. For example, rule \#1 (IF $\mathrm{dP} / \mathrm{dV}$ is "PB" and $\mathrm{dV}$ is "PB", then PT is "PZ") and rule \#2 (IF dP/dV is "PS" and dV is "PS", then PT is "PS") can be simultaneously activated, when the FLC detects incoming input pairs, $\{d P / d V, d V\}$. This is the outstanding characteristic of the FLC, compared to other binary logic controller. In the sense of statistics, multiple logic consequences will improve the accuracy of final weighted results which are expectation-type solutions. Defuzzification is an inverse procedure with respect to the fuzzification. In the processing of defuzzification, a linguistic output will be translated into a numerical value by adopting a weighting operation. The general expression of such operations is that:

$$
\text { Next perturbation } \frac{\sum u_{A_{i}}(x) \times B_{i}}{\sum u_{A_{i}}(x)}
$$

where $u_{A_{i}}(x)$ is the membership function of the output variable fuzzy set and $B_{i}$ is the fuzzy set's numerical solution.

\subsection{Rule Base Tuning}

Every rule in the rule base presents one possible reasoning. The effectiveness and rationality of every rule determines the overall performance of the FLC. The traces shown in Figure 3 present a simple reasoning logic: if the previous perturbation can result in an increase in PV power, the next perturbation in PV voltage will follow the previous direction with the same offset, and vice versa. However, it is not sufficiently effective. As discussed at the beginning of this section, the perturbation offset should be adaptive in order to accelerate tracking process and to suppress the power oscillation around the MPP. Therefore, several reasoning rules can be added, i.e.,:

$\mathrm{IF} \mathrm{dP} / \mathrm{dV}$ is "PB" and $\mathrm{dV}$ is "PB", then $\mathrm{PT}$ is " $\mathrm{PB}$ "

$\mathrm{IF} \mathrm{dP} / \mathrm{dV}$ is "PB" and $\mathrm{dV}$ is "PS", then $\mathrm{PT}$ is "PB"

$\mathrm{IF} \mathrm{dP} / \mathrm{dV}$ is "NB" and $\mathrm{dV}$ is "NS", then $\mathrm{PT}$ is "NB"

$\mathrm{IF} d \mathrm{P} / \mathrm{dV}$ is "NB" and $\mathrm{dV}$ is "NB", then PT is "NB"

The above rules can efficiently push the operation point towards the MPP within a few steps, when the operation point is far from the MPP. However, they are not efficient when the operation point approaches the transition areas where the slope of the P-V curve rapidly increases or decreases. Additionally, considering that the operation point may not move along a single $\mathrm{P}-\mathrm{V}$ curve due to the environmental changes, the incremental changes in PV power may not be meaningful, in real 
environmental conditions. Figure 6 illustrates several conditions which may lead the FLC to make wrong decisions. As seen in Figure 9a, the first perturbation pushes the operation point from $P_{1}$ to $P_{2}$ when the large incremental change in PV power is detected, while at this moment, if the FLC cannot detect the fact that the operation point being located at $P_{2}$ is near MPP, the FLC will probably keep perturbing the operation point to the right with a large perturbation offset. If so, the operation point could be shifted to $P_{3}$. Given the hill shape of P-V curves, the incremental change between $P_{2}$ and $P_{3}$ may be still positive so that the operation point could be further perturbed to $P_{4}$. Then, wrong decisions will be made. Moreover, wrong decisions generated by the FLC may not be easily found because the process shown in Figure 9 is invisible. Other conditions that can result in wrong decisions are presented by Figure 9c,d. Assuming that the FLC changes the perturbation offset in a timely manner, the operation point moves slowly towards the MPP. However, if the environmental conditions, such as irradiation and temperature, change the $\mathrm{P}-\mathrm{V}$ characteristics of photovoltaics will vary immediately. As seen in Figure 9c, irradiation increasing makes the operation point move to another P-V curve so that the incremental change in PV power between $P_{2}$ and $P_{3}$ is enlarged. The FLC may consider that the operation point is far from the MPP, whereas $P_{3}$ is actually close to the new MPP. Therefore, the operation point could be perturbed from $P_{3}$ to $P_{4}$. Given the Figure $9 \mathrm{~d}$, an irradiation drop or temperature increase could also lead the FLC to make wrong decisions again.

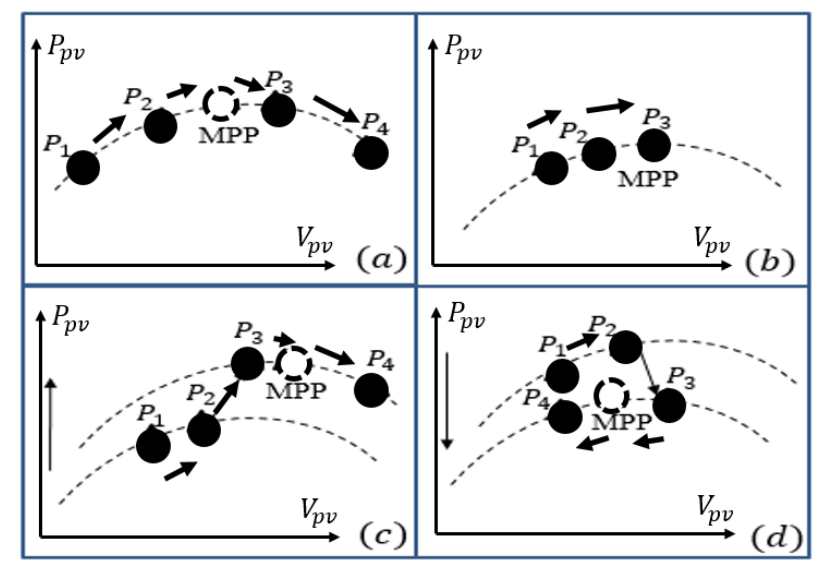

Figure 9. Unexpected problems.

The problems shown in Figure 9 can be solved by adding a slope-detection mechanism into the rule base of FLC. A minimum perturbation is mandatorily fulfilled after the FLC implements its previous reasoning decision. The minimum perturbation can help the FLC to detect the changes of the $\mathrm{P}-\mathrm{V}$ curve with the minimum trade-off. If a rapidly incremental change in PV power can be detected by fulfilling the minimum perturbation in PV voltage, environmental changes can be inferred. If so, the FLC will abandon previous reasoning, and reconsider the status of the operation point and updated $\mathrm{P}-\mathrm{V}$ curve. Including the self-calibration mechanism, the rule-base of the proposed FLC is shown in Table 1.

Table 1. Rule base of the proposed FLC.

\begin{tabular}{|c|c|c|c|c|c|c|}
\hline $\begin{array}{ll}\mathrm{dV} & \mathrm{dP} / \mathrm{dV}\end{array}$ & NB & NS & NZ & PZ & PS & PB \\
\hline NB & NZ & NZ & NZ & PZ & PZ & PZ \\
\hline NS & NZ & NZ & NZ & PZ & PZ & PZ \\
\hline NZ & NB & NS & $\mathrm{NZ}$ & PZ & PZ & PZ \\
\hline PZ & NZ & $\mathrm{NZ}$ & $\mathrm{NZ}$ & PZ & PS & PB \\
\hline PS & NZ & NZ & $\mathrm{NZ}$ & PZ & PZ & PZ \\
\hline PB & NZ & NZ & $\mathrm{NZ}$ & PZ & PZ & PZ \\
\hline
\end{tabular}




\section{Results}

\subsection{Simulations}

To validate theoretical advantages of the proposed fuzzy logic controller, the following MATLAB/SIMULINK simulations present the performance of the conventional $\mathrm{P}$ and $\mathrm{O}$ algorithm with a fixed perturbation intensity $0.1 \mathrm{~V} /$ trial and proposed FLC with adaptive perturbation intensities. The configuration of the simulation is shown in Table 2.

Table 2. Configuration of the simulation.

\begin{tabular}{|c|c|}
\hline \multicolumn{2}{|c|}{ Parameters of the Simulated Solar Panel @ STC } \\
\hline Short circuit current, $I_{S C}$ & $4.75 \mathrm{~A}$ \\
\hline Open circuit voltage, $V_{o c}$ & $27.03 \mathrm{~V}$ \\
\hline Maximum power, $P_{m p p}$ & $98.23 \mathrm{~W}$ \\
\hline \multicolumn{2}{|c|}{ Configuration Settings } \\
\hline Initial operation point $(V, P)$ & $0 \mathrm{~V}, 0 \mathrm{~W}$ \\
\hline Perturbation offset of $\mathrm{P}$ and $\mathrm{O}$ & $0.1 \mathrm{~V}$ \\
\hline Perturbation interval & $100 \mathrm{~ms}$ \\
\hline Temperature condition, $T$ & $25{ }^{\circ} \mathrm{C}$ \\
\hline
\end{tabular}

To test the performance of the improved MPPT algorithm using FLC, several irradiation changes are added into the simulation so that the fast and smooth power transitions (caused by the changes of P-V characteristics of the simulated PV cells) conducted by the proposed FLC can be observed. The MATLAB/Simulink block fulfilling the functionalities of the FLC is shown in Figure 10.

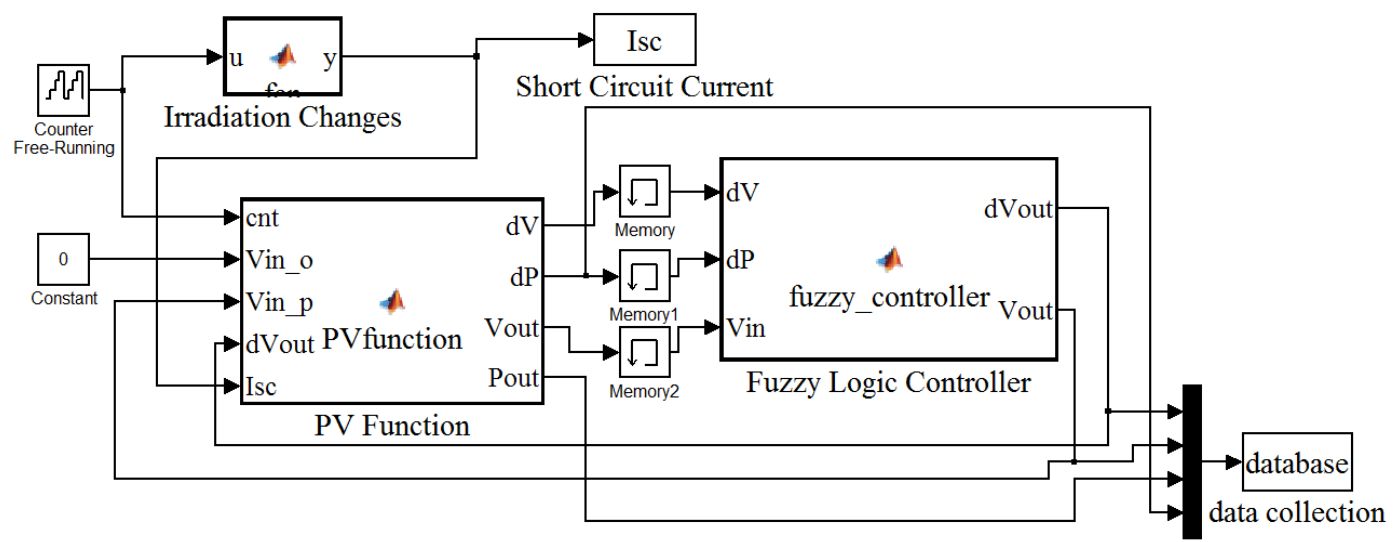

Figure 10. The MATLAB/Simulink diagrams of the FLC.

The membership functions of the FLC can be tuned for achieving better performances in terms of initial tracking time and transition responses, according to practical characteristics of solar panels. Based on the parameters given by Table 2, the output surface of the FLC is decided as is shown in Figure 11. Irradiation variations are represented by the changes in PV short-circuit current shown in Figure 12. To track the initial MPP, the proposed algorithm uses $0.2 \mathrm{~s}$, while the conventional P and $\mathrm{O}$ algorithm uses $2.2 \mathrm{~s}$ in Figure 13. The initial tracking time is shown in Figures 13 and 14. The first and second transition periods of the two simulated algorithms are demonstrated by Figures 15 and 16. As seen in these two figures, the theoretical advantages of the proposed algorithm using FLC can be confirmed. 


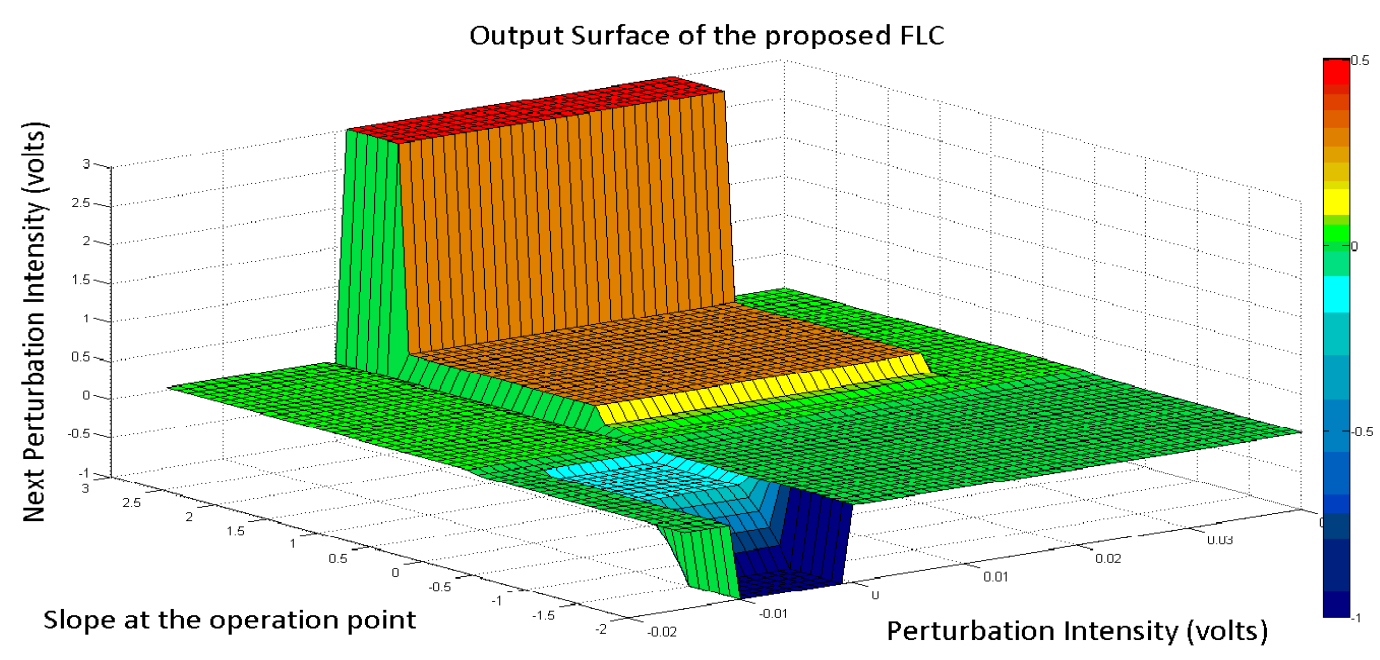

Figure 11. The output surfaces of the FLC.

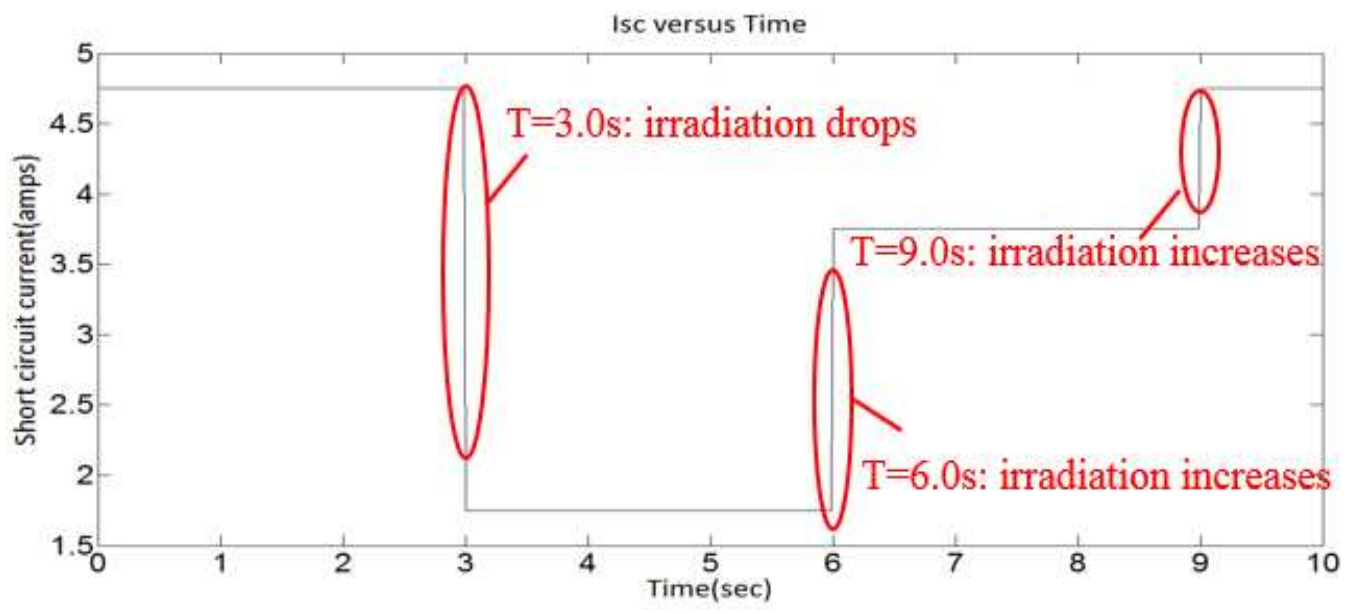

Figure 12. $\mathrm{I}_{\mathrm{sc}}$ vs. time.

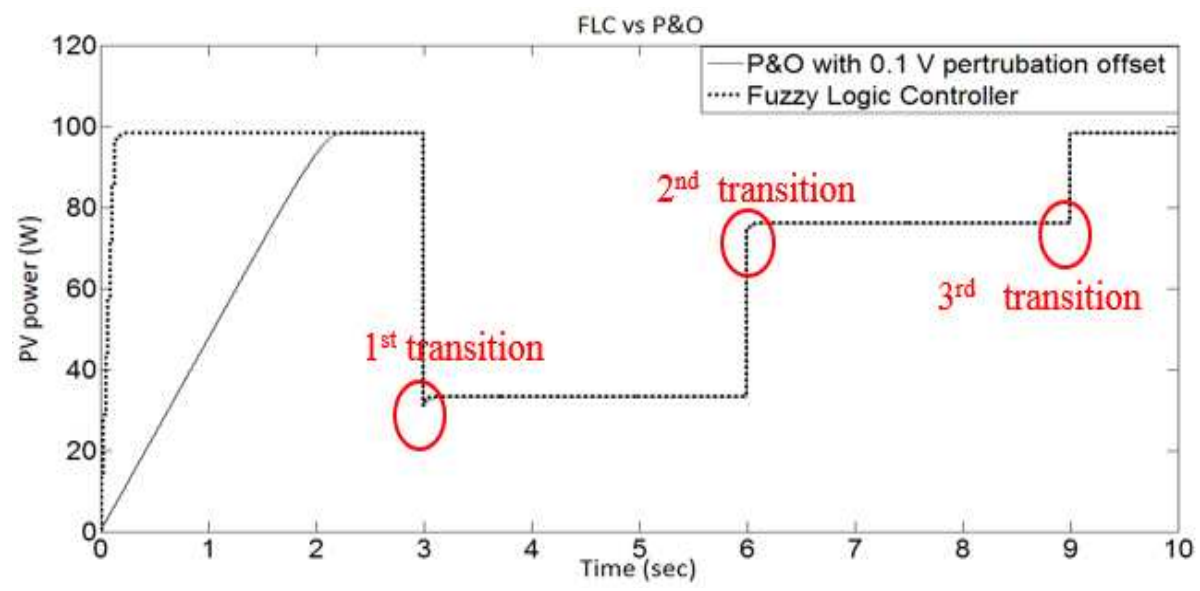

Figure 13. The proposed algorithm (FLC) vs. the conventional $\mathrm{P}$ and $\mathrm{O}$ algorithm. 


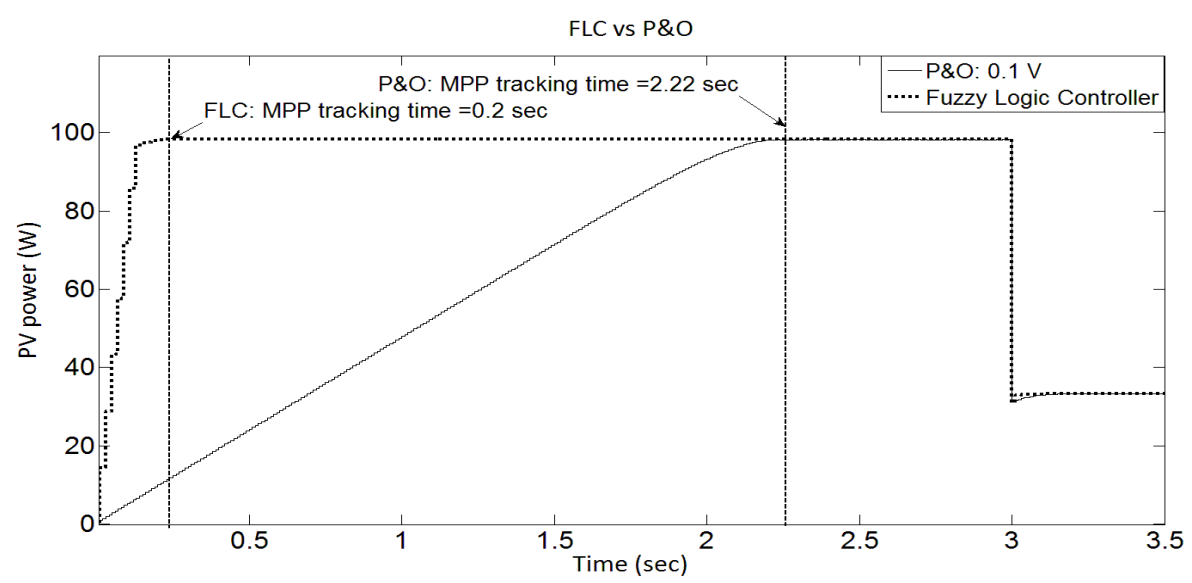

Figure 14. Initial tracking time: FLC vs. $\mathrm{P}$ and $\mathrm{O}(0.1 \mathrm{~V})$.

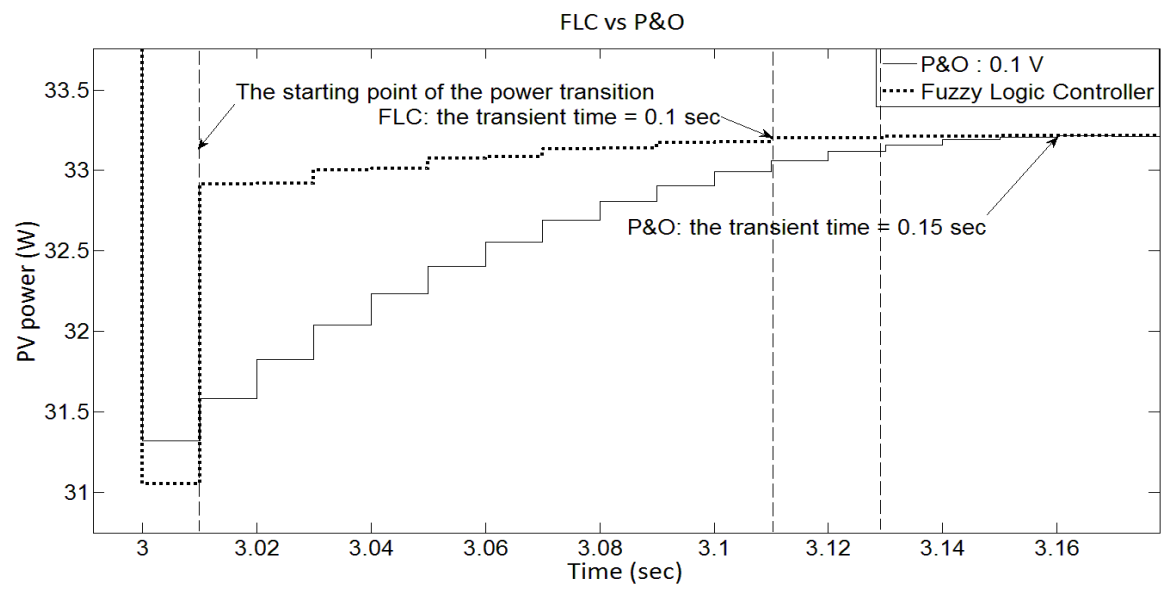

Figure 15. First transition caused by the irradiation drop.

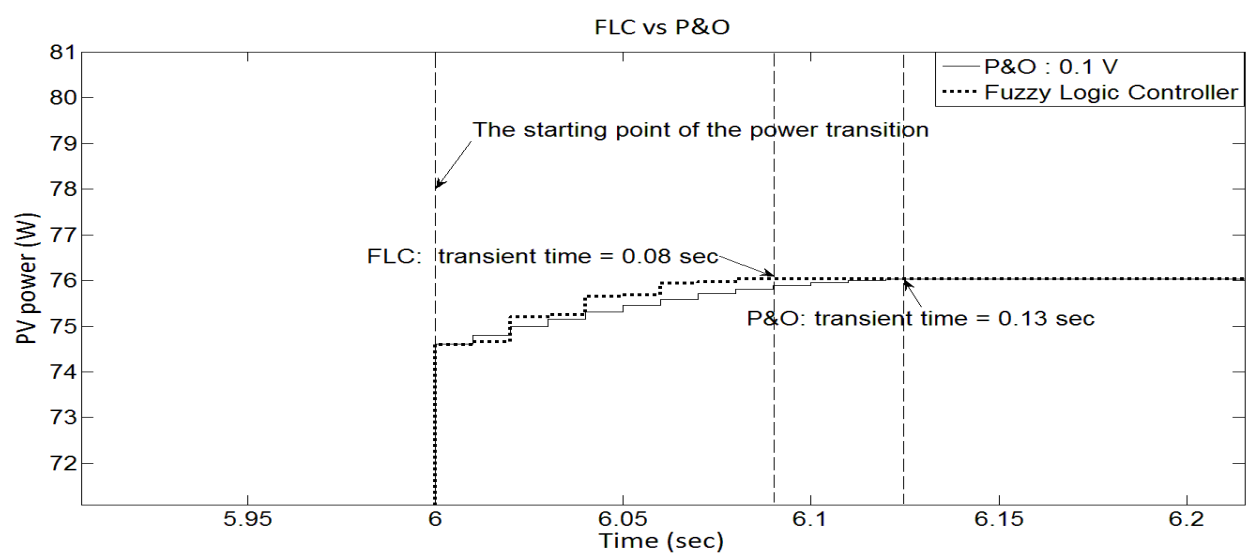

Figure 16. Second transition caused by the irradiation increasing.

\subsection{Experimental Results}

To validate the practical performance of the proposed algorithm in terms of tracking velocity of MPPT and MPPT efficiency, a small scale PV system is built. In the PV system, DSP controlled boost DC-DC converter is implemented for the voltage regulation of the PV system and this boost converter can transfer the PV power to a $26 \mathrm{~V}$ DC-link voltage which is connected to two $13 \mathrm{~V}$ lead acid batteries. The sunlight is simulated by two generic $50 \mathrm{~W}$ electrical light bulbs. Under the test conditions given by 
Table 3, the Boulder $15 \mathrm{~W}$ can maximally generate $3.1 \mathrm{~W}$ of power. The practical MPPT efficiency [29] can be calculated by the Equation (4)

$$
\eta_{M P P T}=\frac{\text { average power conducted by algorithm }}{\text { the potential MPP }}
$$

\section{DC-DC Boost Converter}

The objective of the boost DC-DC converter is to force the PV voltage to converge the reference value which is provided by the MPPT algorithm. Perturbing the duty ratio of the PWM signal, which is fed into the converter, can rebuild the steady-state proportion between the input voltage and output voltage. The transient response of the input terminal may not be always satisfied due to the nonlinear characteristics of the switching-mode circuit and to unknown dynamics. Hence, a voltage controller is normally added into the inner control loop of a photovoltaic system in order to fulfill the voltage regulation of PVs and to improve the transient responses.

The topology of the photovoltaic boost DC-DC converter is shown in Figure 17. Parameters of the photovoltaic system are listed in Table 3. Characteristics of the Boulder $15 \mathrm{~W}$ operating under test conditions are summarized in Table 4.

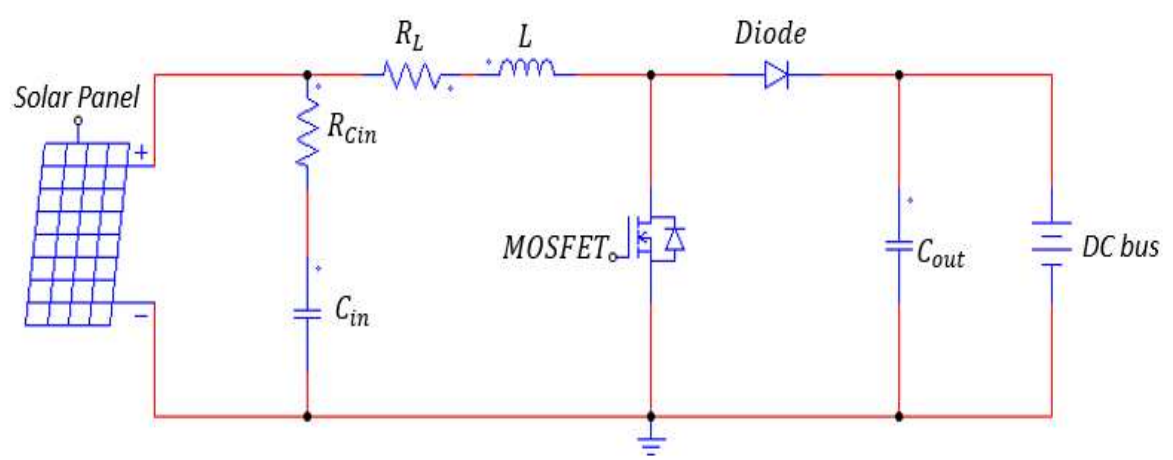

Figure 17. The topology of the photovoltaic boost DC-DC converter.

Table 3. Parameters of the PV system.

\begin{tabular}{cc}
\hline Components & Parameters \\
\hline Solar Panel & Boulder $15 \mathrm{~W}$ \\
$\mathrm{C}_{\text {in }}$ & $35 \mathrm{~V} / 210 \mathrm{uF}$ \\
$\mathrm{R}_{\text {Cin }}$ & $0.8 \Omega$ \\
$\mathrm{L}$ & $12 \mathrm{mH}$ \\
$\mathrm{R}_{\mathrm{L}}$ & $0.2 \Omega$ \\
$\mathrm{C}_{\text {out }}$ & $100 \mathrm{~V} / 1000 \mathrm{uF}$ \\
MOSFET & IRFP460 A \\
Diode & HFA50PA60C \\
DC bus & 26 \\
\hline
\end{tabular}

Table 4. Characterstics of the Boulder $15 \mathrm{~W}$ solar panel.

\begin{tabular}{cc}
\hline Electrical Characteristics & Parameters \\
\hline Open circuit voltage & $17.5-21.4 \mathrm{~V}$ \\
Short circuit current & $0.18-0.22 \mathrm{~A}$ \\
Nominal $\mathrm{V}_{\mathrm{mpp}}$ & $12-17 \mathrm{~V}$ \\
Nominal $\mathrm{I}_{\mathrm{mpp}}$ & $0.166-0.176 \mathrm{~A}$ \\
Maximum power & $2.0-3.1 \mathrm{~W}$ \\
\hline
\end{tabular}

The voltage controller is designed by referring to the small signal model of the input terminal of the photovoltaic system [30-36]. The equivalent circuit of the input terminal is shown in Figure 18. 


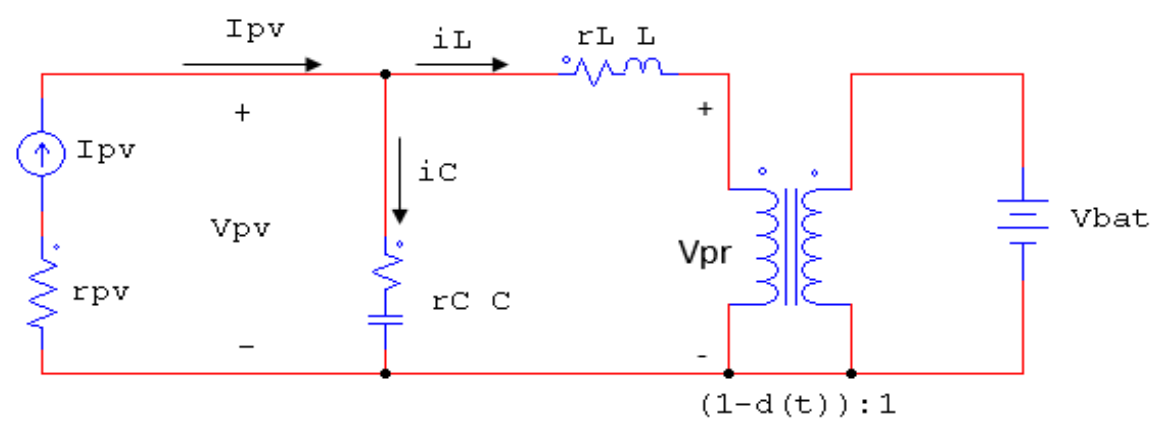

Figure 18. The small signal model of the input terminal.

By applying Kirchhoff's voltage and current laws, the state space equations of the input terminal can be obtained:

$$
\begin{aligned}
& \frac{d}{d t}\left\lceil\frac{\widetilde{I}_{L}}{\widetilde{V_{p v}}}\right\rceil=\left\lceil\begin{array}{cc}
-\frac{R_{L}}{L} & \frac{1}{L} \\
-\frac{R_{p v}\left(1-R_{L} R_{c}\right)}{L C\left(1-R_{p v}\right)} & \frac{C R_{L} R_{c}-1}{L C\left(1-R_{p v}\right)}
\end{array}\right\rceil\left\lceil\frac{\widetilde{I_{L}}}{\widetilde{V_{p v}}}\right\rceil+\left\lceil\left[\begin{array}{c}
\frac{-V_{b a t}}{L} \\
\frac{R_{c} R_{p v} V_{b a t}}{L C\left(1-R_{p v}\right)}
\end{array}\right\rceil \widetilde{d}\right. \\
& \widetilde{y}=\left[\begin{array}{ll}
0 & 1
\end{array}\right]\left[\frac{\widetilde{I_{L}}}{V_{p v}}\right\rceil \\
& G_{v d}(s)=\frac{A}{s^{2}+N s+M}
\end{aligned}
$$

where:

$$
\begin{aligned}
& A=-V_{b a t}\left(\frac{1}{L^{2}}+\frac{R_{c}{ }^{2} R_{p v}{ }^{2}-R_{c} R_{p v}}{L^{2} C\left(1-R_{p v}\right)^{2}}-\frac{R_{c} R_{p v}}{L\left(1-R_{p v}\right)} S\right) \\
& N=\left(\frac{R_{L}}{L}-\frac{R_{c} R_{p v}-1}{L C\left(1-R_{p v}\right)}\right) \\
& M=\frac{R_{L} R_{c} R_{p v}-R_{L}+R_{p v} L-C R_{L}{ }^{2} R_{c} R_{p v}}{L^{2} C\left(1-R_{p v}\right)}
\end{aligned}
$$

Based on the linear approximation of Equation (5), a PI controller is designed as the voltage controller. The digitalized transfer function of the PI controller [37] is given by Equation (6).

$$
G_{P I}(z)=0.1+\frac{0.05}{1-z^{-1}}
$$

The partial embedded code related to the digital PI controller is generated by using MATLAB/Simulink Embedded Coder Toolbox. The Simulink diagram for the embedded coder is shown in Figure 19. A $0.5 \mathrm{~V}$ step response of the inner control loop of the photovoltaic system is illustrated by Figure 20.

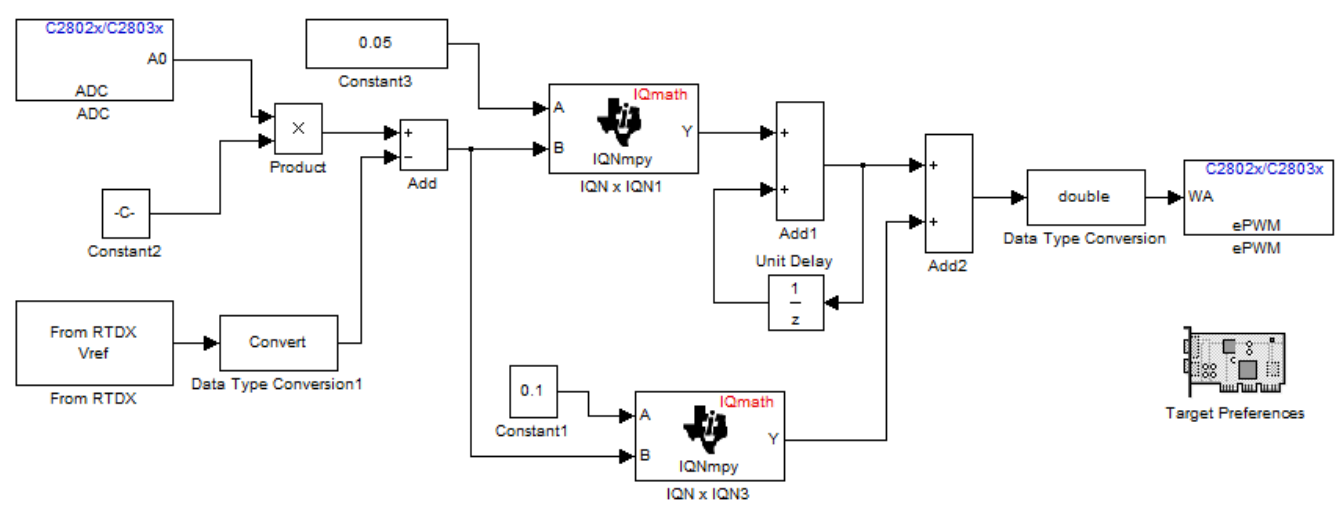

Figure 19. MATLAB/Simulink diagram of the PI controller. 


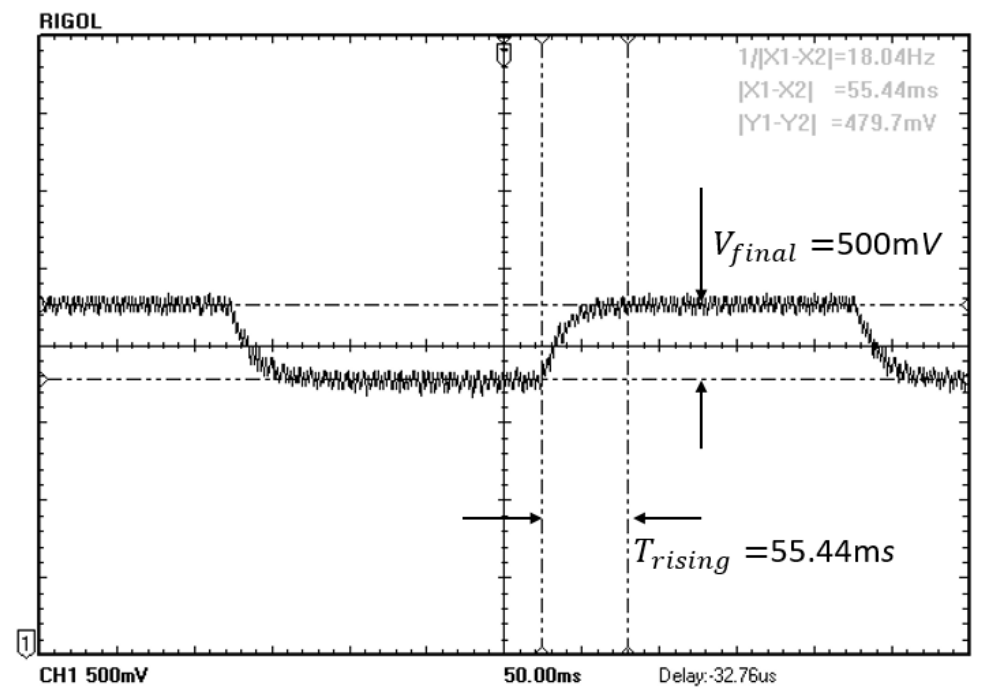

Figure 20. The step response of the inner control loop of the PV system.

The experimental setup of the designed photovoltaic system is shown in Figure 21. The practical performance of the improved $\mathrm{P}$ and $\mathrm{O}$ algorithm using FLC is demonstrated by Figure 22, while that of the conventional $\mathrm{P}$ and $\mathrm{O}$ algorithm with $0.5 \mathrm{~V}$ perturbation offset is shown in Figure 23.

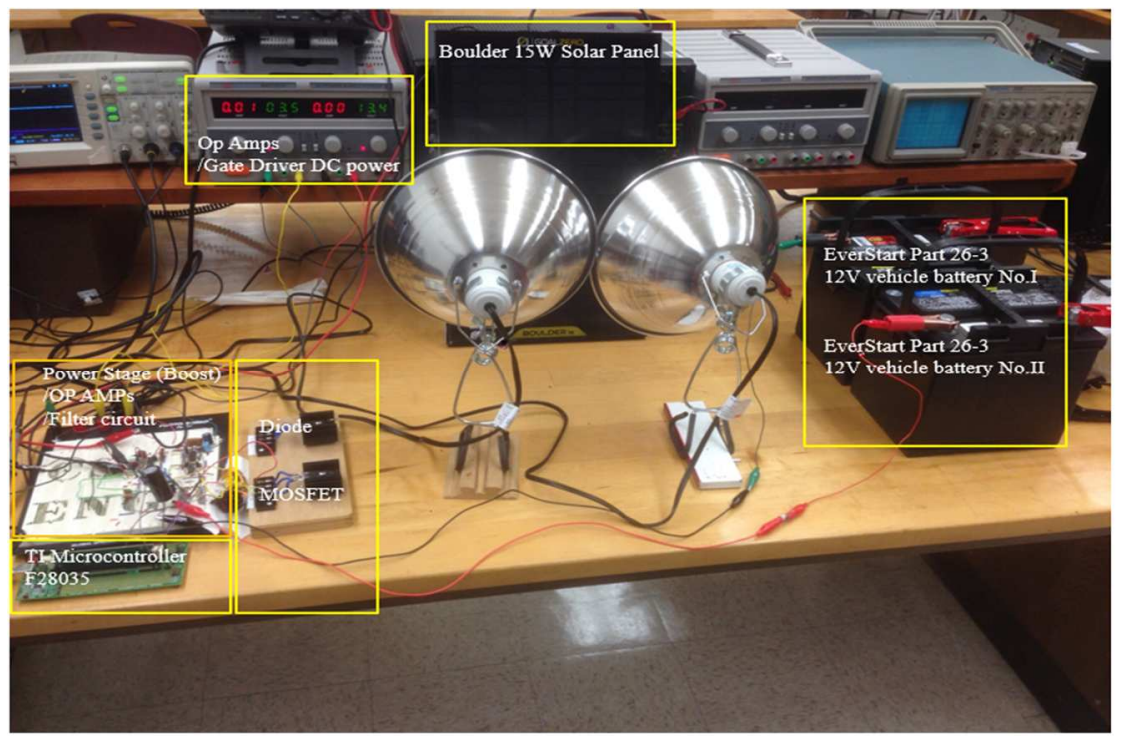

Figure 21. The experimental setup of the photovoltaic system.

The initialized photovoltaic voltage of the Boulder $15 \mathrm{~W}$ is set to $6.0 \mathrm{~V}$. The control interval of outer control loop is set to $200 \mathrm{~ms}$ for successfully covering the settling time of the current sensing circuits. The peak-peak voltage of the circuit noise is controlled around $100 \mathrm{mV}$. Thus, the minimum perturbation offset is set to $200 \mathrm{mV}$ for enhancing the identification of every PV voltage perturbation. To evaluate the system, the fixed perturbation offset of the conventional $\mathrm{P}$ and $\mathrm{O}$ algorithm is set to $500 \mathrm{mV}$. The conventional $\mathrm{P}$ and $\mathrm{O}$ algorithm can extract an average of 2.5 watts power from the solar panel, while the tracking time is $4.32 \mathrm{~s}$ in Figure 22. As seen in Figure 23, the tracking time of the proposed algorithm is $1.81 \mathrm{~s}$, and the extracted PV power is about 3.0 watts. Given Equation (3), the MPPT efficiency of the improved P and O algorithm using FLC is $96.78 \%$, while that of the conventional $\mathrm{P}$ and $\mathrm{O}$ algorithm is only $80.64 \%$. 


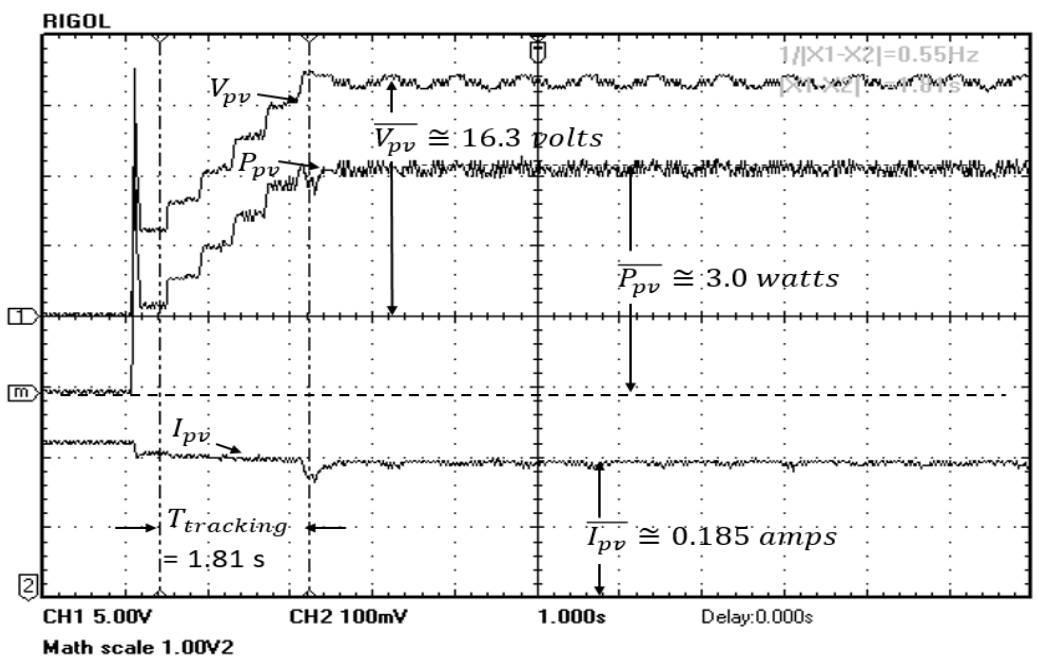

Figure 22. The performance of the conventional $\mathrm{P}$ and $\mathrm{O}$ algorithm.

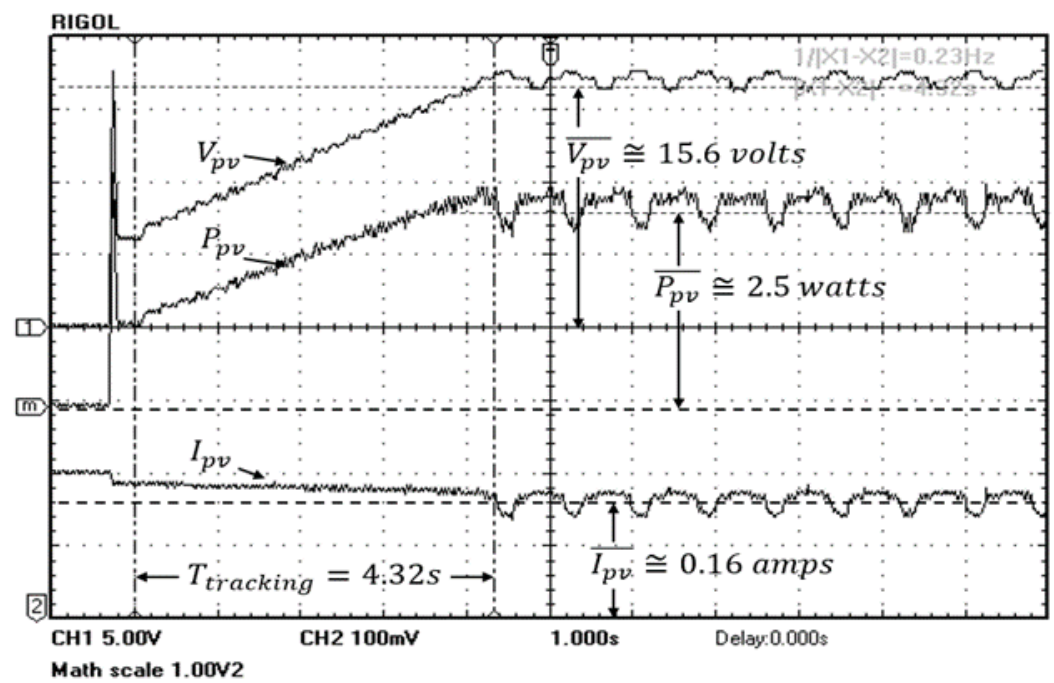

Figure 23. The performance of the proposed fuzzy logic-based algorithm.

\section{Conclusions}

In this paper, an improved $\mathrm{P}$ and $\mathrm{O}$ algorithm using FLC has been proposed by referring to the mechanisms of the conventional $\mathrm{P}$ and $\mathrm{O}$ algorithm and nonlinear characteristics of photovoltaics. The strategy to create adaptive perturbation offsets for accelerating the MPPT velocity and improving the MPPT efficiency were validated by the simulation and experimental results. As mentioned in this paper, the tracking range and perturbation offset determine the overall performance of the MPPT control strategies. In practice, although the P-V characteristics of PVs could frequently vary due to the temperature, shading, and irradiation conditions, especially on a cloudy day, a self-checking mechanism that is embedded into the proposed fuzzy rule base can be easily activated under changes of temperature, shading, and irradiation conditions.

Acknowledgments: This work was supported by the Human Resource Training Program for Regional Innovation and Creativity through the Ministry of Education and National Research Foundation of Korea (NRF-2014H1C1A1066713) and National R\&D Program through the National Research Foundation of Korea (NRF) funded by the Ministry of Science, ICT \& Future Planning (NRF-2016M1A3A1A02021173).

Author Contributions: W.N. and P.C. conceived and designed the experiments; P.C. performed the experiments; P.C., W.N., and J.K. analyzed the data; W.N., P.C., and J.K. wrote the paper. 
Conflicts of Interest: The authors declare no conflict of interest.

\section{References}

1. Fathpour, S.; Tsia, K.K.; Jalali, B. Nonlinear Photovoltaic effect. In Proceedings of the 20th Annual Meeting of the IEEE on Lasers and Electro-Optics Society (LEOS 2007), Lake Buena Vista, FL, USA, 21-25 October 2007; pp. 892-893.

2. Elgendy, M.A.; Zahawi, B.; Atkinson, D.J. Assessment of the Incremental Conductance Maximum Power Point Tracking Algorithm. IEEE Trans. Sustain. Energy 2012, 4, 108-117. [CrossRef]

3. Subudhi, B.; Pradhan, R. A comparative study on maximum power point tracking techniques for photovoltaic power systems. IEEE Trans. Sustain. Energy 2013, 4, 89-98. [CrossRef]

4. Kollimalla, S.K.; Mishra, M.K. A Novel Adaptive P\&O MPPT Algorithm Considering Sudden Changes in the Irradiance. IEEE Trans. Energy Convers. 2014, 29, 602-610.

5. El Basri, Y.; Lahore, C.; Seguier, L.; Ramond, A.; Carrejo, C.; Alonso, C. Adaptive Digital Synchronous P\&O algorithm for Photovoltaic DC Power Conversion. In Proceedings of the 2013 IEEE International Symposium on Industrial Electronics (ISIE), Taipei, Taiwan, 28-31 May 2013; pp. 1-6.

6. Khaehintung, N.; Wiangtong, T.; Sirisuk, P. FPGA Implementation of MPPT Using Variable Step-Size P\&O Algorithm for PV Applications. In Proceedings of the International Symposium on Communications and Information Technologies (ISCIT '06), Bangkok, Thailand, 18-20 October 2006; pp. 212-215.

7. Chu, C.C.; Chen, C.L. Robust maximum power point tracking method for photovoltaic cells: A sliding mode control approach. Sol. Energy 2009, 83, 1370-1378. [CrossRef]

8. Yue, G.; He, H. The research of photovoltaic MPPT controller based on DSPF2812. In Proceedings of the 2014 International Symposium on Computer, Consumer and Control (IS3C), Taichung, Taiwan, 10-12 June 2014; pp. 78-81.

9. Seyedmahmoudian, M.; Rahmani, R.; Mekhilef, S. Simulation and hardware implementation of new maximum power point tracking technique for partially shaded PV system using hybrid DEPSO method. IEEE Trans. Sustain. Energy 2015, 6, 850-862. [CrossRef]

10. Dzung, P.Q.; Lee, H.H.; Vu, N.T.D. The new MPPT algorithm using ANN-based PV. In Proceedings of the 2010 International Forum on Strategic Technology (IFOST), Ulsan, Korea, 13-15 October 2010; pp. $402-407$.

11. Anzalchi, A.; Sarwat, A. Artifical neural network based Duty Cycle estimation for maximum Power Point tracking in Photovoltaic systems. SoutheastCon 2015, 1-5. [CrossRef]

12. Messalti, S.; Harrag, A.G.; Loukriz, A.E. A New Neural Networks MPPT controller for PV Systems. In Proceedings of the 2015 6th International Renewable Energy Congress (IREC), Sousse, Tunisia, 24-26 March 2015; pp. 1-6.

13. Lin, W.M.; Hong, C. M.; Chen, C.H. Neural-Network-Based MPPT Control of a Stand-Alone Hybrid Power Generation System. IEEE Trans. Power Electron. 2011, 26, 3571-3581. [CrossRef]

14. El Khateb, A.; Rahim, N.A.; Selvaraj, J.; Uddin, M.N. Fuzzy-Logic-Controller-Based SEPIC Converter for Maximum Power Point Tracking. IEEE Trans. Ind. Appl. 2014, 50, 2349-2358. [CrossRef]

15. Al Nabulsi, A.; Dhaouadi, R. Efficiency Optimization of a DSP-Based Standalone PV system Using Fuzzy Logic and Dual-MPPT Control. IEEE Trans. Ind. Inform. 2012, 8, 573-584. [CrossRef]

16. Masoum, M.A.S.; Sarvi, M. Design, simulation and construction of a new fuzzy-based maximum power point tracker for photovoltaic applications. Iran. J. Sci. Technol. 2005, 29, 1-10.

17. Kumar, A.P.; Parimi, A.M.; Rao, K.U. Implementation of MPPT control using fuzzy logic in solar-wind hybrid power system. In Proceedings of the 2015 IEEE International Conference on Signal Processing, Informatics, Communication and Energy Systems (SPICES), Kozhikode, India, 19-21 February 2015; pp. 1-5.

18. Verma, A.K.; Singh, B.; Shahani, D.T. Fuzzy-logic based MPPT control of grid interfaced PV generating system with improved power quality. In Proceedings of the 2012 IEEE 5th on Power India Conference, Haryana, India, 19-22 December 2012; pp. 1-6.

19. Alajmi, B.N. Fuzzy-Logic-Control Approach of a Modified Hill-Climbing Method for Maximum Power Point in Microgrid Standalone Photovoltaic System. IEEE Trans. Power Electron. 2010, 26, 1022-1030. [CrossRef]

20. Karatepe, E.; Hiyama, T. Artificial neural network-polar coordinated fuzzy controller based maximum power point tracking control under partially shaded conditions. Renew. Power Gener. IET 2009, 3, 239-253. 
21. Panda, A.; Pathak, M.K.; Srivastava, S.P. Fuzzy Intelligent Controller for the Maximum PowerPoint Tracking of a Photovoltaic Module at Varying Atmospheric Conditions. J. Energy Technol. Policy 2011, 1, 18-27.

22. Soufi, Y.; Bechouat, M.; Kahla, S.; Bouallegue, K. Maximum Power Point Tracking using Fuzzy Logic Control for Photovoltaic System. In Proceedings of the 2014 International Conference on Renewable Energy Research and Application (ICRERA), Milwaukee, WI, USA, 19-22 October 2014; pp. 902-906.

23. Seyedmahmoudian, M.; Rahmani, R.; Mekhilef, S. Implementation of fuzzy logic maximum power point tracking controller for photovoltaic system. Am. J. Appl. Sci. 2013, 10, 209-218.

24. (2013, August). Sunmodule Plus SW 260 Mono. Available online: http://www.solarworld-usa.com/ technical-downloads/datasheets (accessed on 23 August 2013).

25. Ishaque, K.; Salam, Z.; Taheri, H. Accurate MATLAB Simulink PV System Simulator based on a Two-Diode Model. J. Power Electron. 2011, 11, 179-187. [CrossRef]

26. Hanitsch, R.E.; Schulz, D.; Siegfried, U. Sading Effects on Output Power of Grid Connected Photovoltaic Generator Systems. Energy Ren Power Eng. 2001, 93-99.

27. Villalva, M.G.; Gazoli, J.R.; Filho, E.R. Comprehensive Approach to Modeling and Simulation of Photovoltaic Arrays. IEEE Trans. Power. Electron. 2009, 24, 1198-1208. [CrossRef]

28. Engelbrecht, A.P. Fuzzy Systems. In Computational Intelligence, 2th ed.; University of Pretoria South Africa: Pretoria, South Africa, 2007; Chapter VI; pp. 451-485.

29. Valentini, M.; Raducu, A.; Sera, D.; Teodorescu, R. PV inverter test setup for European efficiency, static and dynamic MPPT efficiency evaluation. In Proceedings of the 11th International Conference on Optimization of Electrical and Electronic Equipment (OPTIM 2008), Brasov, Romania, 22-24 May 2008; pp. 433-438.

30. Xiao, W.; Dunford, W.G.; Palmer, P.R.; Capel, A. Regulation of Photovoltaic Voltage. IEEE Trans. Ind. Electron. 2007, 54, 1365-1374. [CrossRef]

31. Villalva, M.G.; Filho, E.R. Dynamic Analysis of the input-controlled buck converter fed by a photovoltaic array. Rev. Control Autom. 2008, 19, 463-474. [CrossRef]

32. Koizumi, H.; Mizuno, T.; Kaito, T.; Noda, Y.; Goshima, N.; Kawasaki, M.; Nagasaka, K.; Kurokawa, K. A novel microcontroller for grid-connected photovoltaic systems. IEEE Trans. Ind. Electron. 2006, 53, 1889-1897. [CrossRef]

33. Bryant, B.; Kazimierczuk, M.K. Voltage Loop of Boost PWM DC-DC Converters. IEEE Trans. Circuits Syst. 2006, 53, 99-105. [CrossRef]

34. Middlebrook, R.D. Small-signal modeling of pulse-width modulated switched-mode power converters. Proc. IEEE 1988, 76, 343-354. [CrossRef]

35. Villalva, M.G.; de Siqueira, T.G.; Ruppert, E. Voltage regulation of photovoltaic arrays: Small-signal analysis and control design. Power Electron. IET 2010, 3, 869-880. [CrossRef]

36. Mohan, N. Designing feedback controllers in switch-mode DC power suppliers. In Power Electronics A First Course; John Wiley \& Sons, Inc.: New York, NY, USA, 2009.

37. Ogata, K. PID Controllers and Modified PID Controllers. In Modern Control Engineering, 5th ed.; Prentice Hall, Inc.: Upper Saddle River, NJ, USA, 2009; pp. 567-641.

(C) 2017 by the authors. Licensee MDPI, Basel, Switzerland. This article is an open access article distributed under the terms and conditions of the Creative Commons Attribution (CC BY) license (http:/ / creativecommons.org/licenses/by/4.0/). 